\title{
ROLE OF THERAPEUTIC DRUG MONITORING AND CHALLENGES IN THE MANAGEMENT OF INFANTILE CHRONIC MYELOID LEUKEMIA
}

\author{
Sneha Tandon ${ }^{1}$, Raviraj Deshpande ${ }^{2}$, Gaurav Narula ${ }^{3}$, Maya Prasad $^{3}$, Amey Paradkar ${ }^{3}$, Vikram Gota $^{2}$, S. D. \\ Banavali3. \\ ${ }^{1}$ Division of Pediatric Hematology Oncology, Department of Pediatrics, University Hospital Southampton, \\ United Kingdom; \\ 2Department of Clinical Pharmacology, ACTREC, Mumbai, India; \\ ${ }^{3}$ Department of Pediatric Oncology, Tata Memorial Centre, Mumbai, India.
}

\begin{abstract}
Chronic myeloid leukemia (CML) is a rare pediatric cancer, more so in children below four years of age. Treating infants with CML can be challenging especially with ensuring compliance to therapy. We report two infants with adult type $\mathrm{CML}$ and the role of therapeutic drug monitoring (TDM) during tyrosine kinase inhibitor therapy (TKI) therapy in their treatment.
\end{abstract}

\author{
ARTICLE HISTORY \\ Received 17 July 2020 \\ Accepted 5 December 2020 \\ KEYWORDS \\ infantile $C M L$, imatinib, \\ therapeutic drug monitoring
}

\section{Introduction}

Chronic myeloid leukemia (CML) is a clonal hematopoietic stem cell disorder and accounts for $3 \%$ of all pediatric leukemias, with an annual incidence of less than 1 case per $1,000,000$ population below 20 years of age. $1,2,3,5 \mathrm{CML}$ classically evolves through three stages; chronic phase (CP), accelerated phase (AP) and blast crisis (BC) with majority presenting as CP. ${ }^{5}$ Adult type $\mathrm{CML}$ is rare in children, especially in children below four years of age, with only two published case reports in this age group. ${ }^{1,2}$ Although CML has been diagnosed in infants as young as 3 months, more than $80 \%$ of pediatric cases of CML are diagnosed after 4 years of age and $60 \%$ after 6 years of age. ${ }^{4,5}$

Tyrosine kinase inhibitors (TKIs) have resulted in a paradigm shift in the treatment of children with CML; have induced deep remission and improved outcomes in pediatric CML population. ${ }^{3}$ However, limited data is available regarding their pharmacokinetics in children. Therapeutic drug monitoring (TDM) for imatinib may provide useful added information on efficacy, safety and compliance than clinical assessment alone and it may impact clinical judgement. It may be beneficial in those with suboptimal response or treatment failure or those with severe adverse reactions. $5,6,7,8,9,10$ In fact, it may be particularly helpful in infants and young children, where it may be a surrogate for compliance as well as help in gauging therapeutic response. Studies have demonstrated relationship between trough plasma imatinib concentration and cytogenetic and molecular responses so far, as well as have shown that mean trough plasma imatinib levels are significantly higher in patients with a complete cytogenetic response (CCYR) or major molecular response (MMR) at the

Address for Correspondance: Dr. Sneha Tandon, Consultant Pediatric Hematology, Division of Pediatric Oncology, University Hospital Southampton, UK.

Email: sneha25tandon@gmail.com

C2021 Pediatric Oncall time of assessment than in those without, at the same mean daily imatinib dose between the two groups. $6,7,8,9$ Cumulative estimated CCyR and MMR rates also differ among the quartiles of imatinib trough levels $(p=.01$ for CCyR, $p=.02$ for MMR) and on multivariate analysis, imatinib trough concentration can be an independent predictor of the likelihood of CCyR. ${ }^{6,10}$ There was a trend towards a better 5-year event-free survival (EFS) in patients with higher trough imatinib concentrations. Additionally, in order to achieve a satisfactory response to therapy, adequate imatinib trough plasma concentration needs to be achieved and maintained. $6,7,8,9,10$ In two seminal studies, plasma imatinib concentrations of more than 1002 $\mathrm{ng} / \mathrm{ml}$ and more than $1009 \mathrm{ng} / \mathrm{ml}$ were significantly associated with the achievement of good cytogenetic and molecular responses. ${ }^{6,7}$ Hence, it is suggested by Arora et al that ensuring plasma trough concentrations at or above the mean population concentration of 1000 $\mathrm{ng} / \mathrm{ml}$ could be critical for achieving superior rates of CCYR and MMR. ${ }^{10}$ Though biologic behavior and prognosis are identical to that of adult type, we are reporting these two cases because of its rare occurrence as well the use of TDM for guiding therapy in this young pediatric population. TDM for imatinib was performed using HPLC-Dionex UHPLC Ultimate 3000 via High Performance Liquid Chromatography (HPLC). A total of $3 \mathrm{ml}$ of patient's blood in EDTA vacutainer was collected before the morning dose at steady state and serum was obtained by centrifugation and analyzed by HPLC method for measurement of trough levels of imatinib.

\section{Case 1}

A 12-month-old boy with previous congenital cytomegalovirus (CMV) infection with global developmental delay presented with fever and splenohepatomegaly for a month. Full blood count (FBC) and differential showed hemoglobin $11.3 \mathrm{mg} / \mathrm{dL}$, total leukocyte count $130 \mathrm{x}$ $10 \%$ L with blasts $8 \%$ with left shift, basophilia $5 \%$, platelet count $935 \times 10^{9} / \mathrm{L}$ and a high serum LDH of 807 $\mathrm{U} / \mathrm{L}$. Bone marrow aspiration and biopsy were consistent 
with CML CP and Fluorescent in-situ Hybridization (FISH) and RT-PCR were positive for Ph chromosome, with no additional cytogenetic abnormalities. After initial cytoreduction with hydroxyurea, he received imatinib $100 \mathrm{mg}$ once daily from March 2014. TDM for imatinib and correlation with cytogenetic and molecular response was done (Table 1 ). Serum imatinib levels were sub-therapeutic in March 2014; hence imatinib dose was increased to $150 \mathrm{mg}$ daily $\left(340 \mathrm{mg} / \mathrm{m}^{2}\right)$ and administered with apple juice. Subsequent serum imatinib levels were found to be in therapeutic range from April 2014 as shown in Table 1. He achieved complete hematological remission ( $\mathrm{CHR}$ ) at two months, complete cytogenetic response (CCyR) at six months and major molecular response (MMR) at 12 months and was in deep molecular remission at 24 months (Table 1). He continues to be in MMR and in excellent clinical condition at six years from diagnosis and is doing well.

\section{Case 2}

A 12-month old male child presented with progressive pallor and hepatosplenomegaly in November 2011. FBC showed hemoglobin $8.6 \mathrm{~g} / \mathrm{dl}$, total leucocyte counts $86 \times 10^{9} / \mathrm{L}$ with left shift with basophilia $3 \%$, platelet count $250 \times 10^{9} / \mathrm{L}$ and normal liver and renal functions. He was diagnosed as CML CP on bone marrow examination and Fluorescent in-situ Hybridization (FISH) and RT-PCR were positive for $\mathrm{Ph}$ chromosome, with no additional cytogenetic abnormalities and received weight-based dosing of imatinib (100 mg daily). Serial TDM for imatinib was done (Table 1). He attained CHR at three months,
CCyR at nine months after diagnosis. He continued on his initial dose of imatinib and a repeat imatinib TDM was done in September 2014 as he missed his previous appointments. In view of sub-therapeutic levels, imatinib dose was escalated to $100 / 200 \mathrm{mg}$ every other day $\left(270 \mathrm{mg} / \mathrm{m}^{2}\right)$ (Table 1$)$. He attained MMR three and a half years since his initial diagnosis and continues to be in deep molecular remission nine years since his diagnosis and is thriving well.

\section{Discussion}

Amongst all childhood leukemias, CML is a rare entity with an annual incidence of one case per million children. ${ }^{1,3,5}$ Adult type CML is even rarer in children below the age of 5 years..$^{5,11,12}$ Our cases are unique due to onset in infancy. Clinical presentation, diagnostic criteria, biologic behavior and prognosis are similar to adults; however, children usually tend to present with higher median white cell count. Splenomegaly, hepatomegaly, hyperleukocytosis, anemia and symptoms related to leukostasis are more frequently encountered in children. ${ }^{4,5,11}$ This was also seen in our patients.

Studies have shown marked inter-individual variability in the pharmacokinetic and pharmacodynamics of imatinib. Limited data is available in the pediatric population, with majority being phase 1 or 2 studies..$^{2,3}$ Since imatinib is metabolized through CYP3A4 and CYP3A5 enzymes, it has considerable interactions with other concomitantly administered drugs using the same pathway. ${ }^{13}$ Thus, the need arises to monitor drug levels, especially in such young children, in order to optimize therapeutic drug levels and improve clinical outcome. Also, in the

Table 1. Serum Imatinib levels with corresponding cytogenetic and molecular responses

\begin{tabular}{|c|c|c|c|c|c|}
\hline & Time & $\begin{array}{l}\text { Imatinib levels } \\
\text { (Therapeutic } \\
\text { level }>1 \mu \mathrm{g} / \mathrm{ml} \text { ) }\end{array}$ & $\begin{array}{l}\text { Hematological } \\
\text { response }\end{array}$ & $\begin{array}{l}\text { Cytogenetic } \\
\text { response }\end{array}$ & RQ-PCR BCR-ABL \\
\hline \multirow[t]{7}{*}{ Case 1} & $\begin{array}{l}\text { March } 2014 \\
\text { (at diagnosis) }\end{array}$ & 0.98 & - & - & $76.73 \%$ \\
\hline & April 2014 & 3.6 & $\begin{array}{l}\text { Complete Hematological } \\
\text { response }\end{array}$ & & \\
\hline & October 2014 & - & - & CCyR & $0.243 \%$ \\
\hline & March 2015 & - & - & - & $0.037 \%$ (MMR) \\
\hline & April 2015 & 1.34 & - & - & - \\
\hline & March 2016 & - & - & - & $\begin{array}{l}0.017 \% \text { (deep } \\
\text { remission) }\end{array}$ \\
\hline & September 2016 & 2.41 & & & \\
\hline \multirow[t]{6}{*}{ Case 2} & November 2011 & 0.75 & - & NA & NA \\
\hline & January 2012 & & $\begin{array}{l}\text { Complete Hematological } \\
\text { response }\end{array}$ & & \\
\hline & July 2012 & & & CCyR & \\
\hline & September 2014 & 0.7 & & & $0.06 \%$ \\
\hline & July 2015 & 0.62 & & & $0 \%(\mathrm{MMR})$ \\
\hline & July 2017 & 1.65 & & & $0 \%$ (deep response) \\
\hline
\end{tabular}

Note: CCyR - complete cytogenetic response, MMR - major molecular response 
very young patient population, issues arise with the administration of the drug as liquid formulations are unavailable. Our patients received crushed imatinib tablets with apple juice. Imatinib levels were serially monitored in our patient and were found to be in therapeutic range $(>1.0 \mu \mathrm{g} / \mathrm{ml} \text { or } 1000 \mathrm{ng} / \mathrm{ml})^{10}$ at all time-points. These levels were a surrogate in our patient population; both for compliance as well as for assessing the response to treatment. Correlation with cytogenetic and molecular responses was done in our patients, wherein deep remission was seen with therapeutic serum imatinib levels. Our results are similar to those demonstrated across various studies. $6,7,8,9,10$

\section{Conclusion}

CML presenting in infants is unusual with very few reported cases. Our cases highlight the unusual presentation of CML in infancy as well as the challenges encountered in managing these patients during treatment. TDM during TKI therapy could be an adjunct to optimizing therapy for infants with CML.

\section{Acknowledgement}

We would like to acknowledge the contributions of $\mathrm{Dr}$ Brijesh Arora, former member of our Group who was instrumental in initiating the TDM project for imatinib, which made the successful management of these infants possible.

\section{Compliance with Ethical Standards}

Funding: None

Conflict of Interest: None

\section{References:}

1. Chen $\mathrm{Y}$, Wang $\mathrm{H}$, Kantarjian $\mathrm{H}$, Cortes J. Trends in chronic myeloid leukaemia incidence and survival in the United States from 1975 to 2009. Leuk Lymphoma.2013;54:1411-1417.

2. Homans AC, Young PC, Dickerman JD, Land ML. Adult-type CML in childhood: case report and review. Am J Pediatr Hematol Oncol. 1984; 6:220-224.

3. Andolina JR, Neudorf SM, Corey SJ. How I treat childhood CML. Blood 2012;119:1821-1830.
4. Emanuel PD. Myelodysplasia and Myeloproliferative disorders in childhood: an update. $\mathrm{Br}$ J Hematol.1999;105:852-863.

5. Rabinowitz I, Larson RS, Greer JP, Foerster J, Lukens JN, Rodgers GM. Wintrobes clinical hematology. Lippincott Williams and Williams. 11th ed. Vol 2. 2004:2235-2244.

6. Larson RA, Druker BJ, Guilhot F, O'Brien SG, GJ Riviere $\mathrm{GJ}$, Krahnke $T$, et al. Imatinib pharmacokinetics and its correlation with response and safety in chronic-phase chronic myeloid leukemia: a subanalysis of the IRIS study. Blood. 2008;111:4022-4028.

7. Picard S, Titier K, Etienne G, Teilhet E, Ducint D, Bernard $M A$, et al. Trough imatinib plasma levels are associated with both cytogenetic and molecular responses to standard-dose imatinib in chronic myeloid leukemia. Blood. 2007;109:3496-3499.

8. Guilhot F, Hughes TP, Cortes J, Druker BJ, Baccarani M, Gathmann I, et al. Plasma exposure of imatinib and its correlation with clinical response in the Tyrosine Kinase Inhibitor Optimization and Selectivity Trial. Haematologica. 2012; 97:731-738.

9. Takahashi N, Wakita H, Miura M, Scott SA, Nishii K, Masuko $M$, et al. Correlation between imatinib pharmacokinetics and clinical response in Japanese patients with chronicphase chronic myeloid leukemia. Clin Pharmacol Ther. 2010;88:809-813.

10. Arora B, Gota V, Menon H, Senger M, Nair R, Patial P, et al. Therapeutic drug monitoring for imatinib: Current status and Indian experience. Indian J Med and Paediatr Oncol. 2013;34:224-228.

11. Pizzo PA and Paplock DG. Principles and practice of pediatric oncology. 6th ed Wolters Kluwer. 2011:545-559.

12. Mishra A, Tripathi K, Mohanty L, Pujari S. Philadelphia chromosome positive chronic myeloid leukemia in a child: a case report. Indian J Hematol Blood Transfus. 2010;26:109-110.

13. Petain A, Kattygnarath D, Azard J, Chatelut E, Delbaldo C, Geoerger B, et al. Population pharmacokinetics and pharmacogenetics of imatinib in children and adults. Clin Cancer Res.2008;14:7102-7109. 